\title{
Strategi Peningkatan Keterampilan Pramusaji di Makase Restaurant
}

\author{
Ida Ayu Kade Winda Wikantini , Nyoman Dini Andiani \\ Undiksha
}

\begin{abstract}
Abstrak
Penelitian ini bertujuan untuk mengetahui strategi peningkatan keterampilan pramusaji di Makase Restaurant. Subjek penelitian ini adalah Supervisor dan karyawan Makase Restaurant. Objek penelitian ini adalah strategi peningkatan keterampilan pramusaji di Makase Restaurant. Metode pengumpulan data adalah observasi, dokumentasi dan wawancara. Hasil penelitian ini adalah (1) kendala pramusaji dalam melayani tamu di Makase Restaurant adalah keterbatasan bahasa asing karena tidak semua tamu bisa berbahasa Inggris menyebabkan slow service dan tamu complaint. (2) strategi yang digunakan untuk meningkatkan keterampilan pramusaji adalah dengan memberikan pelatihan secara konsisten, uji kompetensi, dan mengadakan kompetisi di hotel yang dapat mempengaruhi kelancaran operasional, meningkatkan kepuasan tamu dan meningkatkan penjualan.
\end{abstract}

Kata Kunci : Strategi, Keterampilan, Pramusaji

\begin{abstract}
This research aims to determine the strategy of upgrading waiter/ss skills at Makase Restaurant. The subject of this study is Supervisor and employee of Makase Restaurant. The object of this study is a strategy to improve the skills of waiter/ss at Makase Restaurant. Data collection methods are observations, documentation and interviews. The results of this research are (1) waiter/ss constraints in serving guests at Makase Restaurant is a limitation of foreign languages because not all guests can speak English cause slow service and guest complaint. (2) the strategy used to improve the skills of waiter/ss is to provide consistent training, competency tests, and hold competitions in hotels that can affect operational smoothness, increase guest satisfaction and increase sales.
\end{abstract}

Key Words : Strategy, Skills, Waiter/ss

\section{Pendahululuan}

Hotel Indigo Bali Seminyak Beach merupakan Hotel Indigo berkonsep resort pertama di dunia dan resmi dibuka untuk umum pada tanggal 1 Juli 2017. Menyediakan 270 kamar dan 19 villas, termasuk spa, 3 restaurant, 2 bar, sebuah coffee shop serta beach house yang ikonik. Salah satu dari 3 restaurant tersebut adalah Makase Restaurant. Makase Restaurant merupakan All Day Dinning Restaurant yang berkonsep Neighborhood Cafe yang terletak di lantai dasar hotel dan menjadi penghubung antara dinning restaurant dan bar. Dengan konsep casual dinning, restaurant ini memadukan cita rasa lokal yaitu cita rasa asli Bali disajikan di tengah konsep dapur terbuka dan dipadukan dengan masakan Western serta masakan Asian lainnya. Melayani breakfast, lunch dan juga dinner dimana untuk jenis breakfast menggunakan buffet dan juga ala carte sedangkan untuk luch dan dinner adalah menu ala carte.

Berdasarkan hasil observasi awal (saat PKL) di Makase Restaurant penulis mengamati bahwa sering kali pramusaji kurang terampil saat menghadapi tamu sehingga menimbulkan masalah seperti kurangnya komunikasi antara tamu dengan pramusaji, tidak mengetahui keinginan tamu dengan jelas sehingga tidak ada interaksi yang baik antara keduanya, tidak ada inisiatif pramusaji dalam bekerja dan hotel membutuhkan pramusaji yang mampu berbahasa asing selain bahasa Inggris seperti Jurnal Manajemen Perhotelan dan Pariwisata | 42 
bahasa Mandarin karena mayoritas pasar berasal dari negara Cina akibatnya tamu merasa kurang puas, merasa tidak nyaman dan memberikan review yang kurang baik terhadap kinerja pramusaji di Makase Restaurant. Berdasarkan uraian latar belakang diatas, maka perlu dianalisis lebih lanjut mengenai : 1. Apa saja kendala seorang pramusaji dalam melayani tamu di Makase Restaurant ? 2. Bagaimana strategi peningkatan keterampilan pramusaji di Makase Restaurant ? Adapun tujuan dari penelitian ini adalah : (1)Untuk mengetahui kendala apa saja yang dialami seorang pramusaji dalam melayani tamu di Makase Restaurant.(2)Untuk mengetahui bagaimana startegi peningkatan ketrampilan pramusaji di Makase Restaurant.

\section{Kajian Pustaka}

Konsep Strategi

Menurut Siagian (2016:29 dalam Sholichah, 2019:13) strategi adalah serangkaian keputusan mendasar yang dibuat oleh manajemen tertinggi dan diaplikasikan oleh semua jajaran dalam suatu organisasi untuk mencapai tujuan. Berdasarkan definisi tersebut strategi merupakan suatu rencana yang diputuskan oleh manajemen tertinggi dan di terapkan dalam organisasi dalam rangka mencapa tujuan. Strategi merupakan kegiatan yang bersifat incremental (senantiasa meningkat) yang terjadi terus menerus dan dilihat dari sudut pandang konsumen mengenai apa yang sebenarnya diinginkan di masa mendatang, maka dari itu strategi dimulai dari apa yang bisa terjadi bukan dari apa yang terjadi. Misalnya strategi untuk mengurangi biaya dalam suatu organisasi, memperbaiki kulitas, dan memperluas pasar.(Hamel dan Prahalad, 2005:31 dalam Melati, 2018:23).

\section{Konsep Ketrampilan}

Wahyudi (2002:33 dalam Sa'diyah, 2018:18) menyatakan keterampilan adalah kemampuan untuk melakukan suatu pekerjaan yang hanya bisa didapatkan melalui praktek. Keterampilan kerja dikelompokan menjadi tiga kategori yaitu :

a. Keterampilan mental seperti menganalisa, menghitung dan menghafal.

b.Keterampilan fisik seperti keterampilan yang berhubungan dengan anggota tubuh dan juga pekerjaan.

c. Keterampilan sosial seperti mampu mempengaruhi orang lain, berpidato atau menawarkan barang.

Salah satu dimensi dari indikator kemampuan yang difokuskan pada teori yang dikemukakan oleh Winardi(2002 dalam Fitria, 2018:129) yaitu Keterampilan (Skill). Keterampilan adalah keahlian dan kecakapan karyawan sebagai gabungan dari bakat dan kepribadian yang dimilikinya. Indikator skill meliputi : mampu menyelesaikan tugas tepat waktu, kreatif, mampu berinovasi, menghitung dengan cepat dan mengoperasikan komputer.

Berdasarkan pengertian keterampilan diatas maka dapat disimpulkan bahwa keterampilan merupakan kemampuan untuk menggunakan akal, fikiran dan ide untuk mengubah sesuatu memiliki makna dan nilai lebih cepat. Keterampilan didapatkan dari kegiatan yang dilakukan secara konsisten Jurnal Manajemen Perhotelan dan Pariwisata | 43 
agar suatu saat menjadi profesional dalam bidang yang di tekuni. Kategori keterampilan meliputi keterampilan mental, fisik, dan sosial. Indikator skill misalnya menyelesaikan tugas dengan cepat, kreatif dan inovatif.

\section{Metodelogi Penelitian}

\section{Rancangan Penelitian}

Dalam rancangan ini menggunakan rancangan penelitian yang bersifat deskriptif kualitatif yatu metode penelitian yang memaparkan hasil data yang diperoleh melalui observasi secara langsung ke lapangan, melakukan wawancara dan dokumentasi yang kemudian dijabarkan ke dalam bentuk pembahasan. Data dan dokumentasi yang telah dikumpulkan akan ditarik menjadi suatu kesimpulan dari permasalahan yang didapatkan pada saat observasi awal pada lokasi penelitian di Makase Restaurant Hotel Indigo Bali Seminyak Beach. Setelah data dirangkum dan diolah maka akan menghasilkan suatu cara atau strategi peningkatan keterampilan pramusaji di Makase Restaurant, dimana sering ditemukan permasalahan saat operasional di restaurant karena kurangnya keterampilan pramusaji. Sumber data berupa data skunder dan primer dengan teknik pengumpulan data yaitu wawancara dengan Supervisor Makase Restaurant.

\section{Lokasi Penelitian}

Penelitian ini dilakukan di Makase Restaurant Hotel Indigo Bali Seminyak Beach yang beralamat di Jln. Camplung Tanduk No.10, Seminyak Bali, Kabupaten Badung, Bali 80361 Telepon : 62-3612099999. Lokasi tersebut dipilih berdasarkan tempat praktek kerja lapangan di Makase Restaurant Hotel Indigo Bali Seminyak Beach terdapat permasalahan saat operasional di restaurant karena kurangnya keterampilan pramusaji saat menghadapi tamu.

\section{Subjek dan Objek Penelitian}

Adapun yang menjadi subjek dalam penelitian ini adalah Supervisor Makase Restaurant yang dapat memberikan informasi terkait penelitian sedangkan yang menjadi objek penelitian adalah peningkatan keterampilan pramusaji di Makase Restuarant Hotel Indigo Bali Seminyak Beach.

\section{Metode Pengumpulan Data dan Instrumen Penelitian}

Dalam penelitian ini untuk memperoleh data menggunakan 3 cara yaitu : metode observasi yang dilaksanakan pada saat PKL selama 6 bulan di bagian food and beverage service departemen , metode wawancara dengan Supervisor Makase Restaurant dan metode dokumentasi dengan foto yangdiambil secara langsung guna mendukung dalam penelitian

\section{Teknik Analisi Data}

Penelitian ini menggunkan teknis analisis data kualitatif Moelong (2008:2) yang berpendapat bahwa penelitian kualitatif merupakan penelitian yang memfokuskan pada 
paparan kalimat, sehingga lebih mampu memahami kondisi psikologi manusia yang komplek (dipengaruhi oleh banyak fakta) yang tidak cukup apabila diukur dengan menggunkan skala saja.

\section{Hasil Penelitian dan Pembahasan}

\section{Kendala Dalam Meningkatkan Kinerja}

Berdasarkan hasil wawancara dengan Bapak I Gusti Ngurah Putu Suma Adi Putra selaku Supervisor Makase Restaurant pada tanggal 24 Mei 2020 menyatakan bahwa Kendala pramusaji dalam memberikan pelayanan di Makase Restaurant adalah upaya penyesuaian terhadap tamu yang memiliki keterbatasan bahasa, tamu yang datang ke Makase restaurant berasal dari berbagai negara dan budaya yang berbeda karena tidak semua tamu bisa berbahasa Inggris seperti tamu yang berasal dari benua Asia yaitu Korea, Thailand, Jepang merupakan negara yang dikenal memiliki bahasa mereka sendiri yang sangat kental. Walaupun tidak semua tamu memiliki keterbatasan bahasa namun saat pramusaji menghadapi tamu yang kurang memahami bahasa Inggris akan merasa kesulitan memahami keinginan tamu yang datang ke Makase Restaurant.

Makase Restaurant menggunakan menu buffet saat breakfast dimana tamu dapat mengambil makanan yang telah disediakan namun tidak berlaku bagi makanan dan minuman yang harus dibuat dalam keadaan fresh atau hangat seperti egg selection (omelette, boil egg, egg benedict, fried egg, poach egg), soup (laksa, miso, clear vegetable, tom yum), fresh juice, coffee, tea, pancake dan waffle. Tamu harus menunggu di meja sampai runner yang akan membawa pesanan tamu. Pada saat memesan, tamu yang tidak mengerti bahasa Inggris banyak yang salah menyebutkan table number atau menyebutkan pesananan yang diinginkan. Tamu akan complaint kepada pramusaji karena pesanan mereka tidak datang dan tidak sesuai keinginan, butuh waktu untuk mencari pemilik pesanan karena table number yang salah sedangkan orderan terus bertambah, hal ini menyebabkan slow service dan tamu merasa kurang puas terhadap pelayanan yang diberikan. Hal ini sering terjadi pada saat occupancy hotel sedang tinggi, pramusaji biasanya akan lebih sensitif karena tamu yang datang secara bersamaan sedangkan ketersediaan table sedang penuh dengan situasi yang sedang padat ditambah dengan complaint dari tamu akan memicu kepanikan pramusaji dalam bekerja menyebabkan miss komunikasi antara pramusaji dengan tamu dan sesama pramusaji. Keterbatasan berbahasa mempengaruhi kelancaran operasional karena pramusaji akan memberi perhatian lebih bagi tamu yang tidak mendapatkan apa yang diinginkan maka pramusaji akan mencoba berinteraksi melalui bahasa tubuh atau isyarat dan menangani complaint dari tamu sehingga pekerjaan yang lain menjadi sedikit tertunda.

\section{Strategi Peningkatan Ketrampilan Pramusaji Di Makase Restaurant}

Berdasarkan hasil wawancara dengan Bapak I Gusti Ngurah Putu Suma Adi Putra selaku Jurnal Manajemen Perhotelan dan Pariwisata | 45 
Supervisor Makase Restaurant pada tanggal 24 Mei 2020 menyatakan bahwa Kendala pramusaji dalam memberikan pelayanan di Makase Restaurant adalah upaya penyesuaian terhadap tamu yang memiliki keterbatasan bahasa, tamu yang datang ke Makase restaurant berasal dari berbagai negara dan budaya yang berbeda karena tidak semua tamu bisa berbahasa Inggris seperti tamu yang berasal dari benua Asia yaitu Korea, Thailand, Jepang merupakan negara yang dikenal memiliki bahasa mereka sendiri yang sangat kental. Walaupun tidak semua tamu memiliki keterbatasan bahasa namun saat pramusaji menghadapi tamu yang kurang memahami bahasa Inggris akan merasa kesulitan memahami keinginan tamu yang datang ke Makase Restaurant.

Makase Restaurant menggunakan menu buffet saat breakfast dimana tamu dapat mengambil makanan yang telah disediakan namun tidak berlaku bagi makanan dan minuman yang harus dibuat dalam keadaan fresh atau hangat seperti egg selection (omelette, boil egg, egg benedict, fried egg, poach egg), soup (laksa, miso, clear vegetable, tom yum), fresh juice, coffee, tea, pancake dan waffle. Tamu harus menunggu di meja sampai runner yang akan membawa pesanan tamu. Pada saat memesan, tamu yang tidak mengerti bahasa Inggris banyak yang salah menyebutkan table number atau menyebutkan pesananan yang diinginkan. Tamu akan complaint kepada pramusaji karena pesanan mereka tidak datang dan tidak sesuai keinginan, butuh waktu untuk mencari pemilik pesanan karena table number yang salah sedangkan orderan terus bertambah, hal ini menyebabkan slow service dan tamu merasa kurang puas terhadap pelayanan yang diberikan. Hal ini sering terjadi pada saat occupancy hotel sedang tinggi, pramusaji biasanya akan lebih sensitif karena tamu yang datang secara bersamaan sedangkan ketersediaan table sedang penuh dengan situasi yang sedang padat ditambah dengan complaint dari tamu akan memicu kepanikan pramusaji dalam bekerja menyebabkan miss komunikasi antara pramusaji dengan tamu dan sesama pramusaji. Keterbatasan berbahasa mempengaruhi kelancaran operasional karena pramusaji akan memberi perhatian lebih bagi tamu yang tidak mendapatkan apa yang diinginkan maka pramusaji akan mencoba berinteraksi melalui bahasa tubuh atau isyarat dan menangani complaint dari tamu sehingga pekerjaan yang lain menjadi sedikit tertunda.

\section{Pembahasan Hasil Penelitian}

Berdasarkan hasil penelitian yang telah saya lakukan pada saat PKL di Makase Restaurant selama 6 bulan terdapat dua persamaan strategi yang digunakan oleh Supervisor Makase Restaurant dalam meningkatkan keterampilan pramusaji dengan tipe-tipe strategi menurut Kooten (dalam Pratama, 2018:13) meliputi :

\section{Corporate Strategy (Strategi Organisasi)}

Strategi ini berisi tentang rumusan, inisiatif-insiatif, tujuan dan nilai strategi yang baru untuk apa dan untuk siapa strategi ini dibuat.

2. Program Strategy (Strategi Program)

Strategi ini mengutamakan dampak yang akan terjadi jika suatu program dilaksanakan 
bagi suatu organisasi.

3. Resources Support Strategy (Strategi Pendukung Sumber Daya)

Strategi ini lebih memperhatikan sumber-sumber daya esensial (tenaga, keuangan, teknologi) yang dianggap bermanfaat untuk meningkatkan kualitas kinerja suatu organisasi.

4. Institusional Strategy (Strategi Kelembagaan)

Strategi ini memberi perhatian pada meningkatkan kemampuan organisasi dalam rangka mencapai tujuan organisasi tersebut.

Tipe-tipe strategi diatas dapat dilihat persamaan dengan hasil penelitian yang telah diterapkan oleh Supervisor di Makase Restaurant adalah menggunakan tipe strategi kelembagaan atau Institusional Strategy dimana strategi yang dikemukakan oleh supervisor Makase Restaurant yaitu memberi perhatian dengan memberikan pelatihan atau training setiap hari setelah briefing seperti training wine, up selling, menu, promotion, dan SOP kepada pramusaji untuk meningkatkan keterampilan pramusaji di Makase Restaurant dalam rangka mencapai tujuan yaitu melancarkan operasional restaurant, meningkatkan kepuasan tamu dan juga pendapatan penjualan makanan di Makase Restaurant. Selain itu strategi program juga diterapkan, dari pihak hotel juga memiliki program yang telah dilaksanakan seperti uji kompetensi untuk semua departemen hotel dan mengadakan kompetisi secara external dan internal dari pelaksanaan program tersebut dampak yang akan terjadi dalam hal positif diharapkan dapat meningkatkan rasa kekeluargaan antar karyawan, meningkatkan kinerja semua karyawan dalam departemen hotel, menumbuhkan daya saing terhadap kompetitor dan sesuai dengan tujuan dari masing-masing departemen.

Keterampilan berasal dari kegiatan yang terus dilakukan berulang-ulang hingga menjadi terbiasa sehingga dapat melakukan tugas atau pekerjaan dengan mudah dan cepat, sama halnya dengan strategi yang diterapkan di Makase Restaurant yaitu melaksanakan pelatihan agar para pramusaji dapat bekerja secara profesional dapat menyelesaikan masalah yang timbul saat operasional dan melaksanakan tugas dan tanggung jawab sebagai seorang pramusaji. Hal ini didukung dengan pernyataan oleh Winardi (2002 dalam Fitria, 2018:129) Keterampilan (Skill) adalah keahlian dan kecakapan karyawan sebagai gabungan dari bakat dan kepribadian yang dimilikinya. Indikator skill meliputi: mampu menyelesaikan tugas tepat waktu, kreatif, mampu berinovasi, menghitung dengan cepat dan mengoperasikan komputer. Pemberian pelatihan kepada semua pramusaji sangat penting dilaksanakan secara rutin melalui teori dan praktek langsung dari atasan karena dapat memberikan ruang bagi pramusaji dalam mengembangkan potensinya agar lebih terasah, mengenal hal-hal baru, melatih cara berkomunikasi yang baik antar atasan, teman kerja dan juga tamu, dapat menambah wawasan, keterampilan untuk pramusaji sehingga dapat menyelesaikan pekerjaan dengan cepat dan mudah. Pernyataan ini didukung oleh Iverson (2001 dalam Darba, 2019:24) "keterampilan membutuhkan pelatihan dan kemampuan dasar yang dimiliki setiap orang dapat lebih membantu menghasilkan sesuatu yang lebih bernilai dengan lebih cepat".

Penilaian yang dilakukan oleh pihak atasan terhadap kinerja pramusaji di Makase Restaurant 
mengacu pada beberapa syarat dan sifat pramusaji yang dikemukakan oleh Marsum WA (2001:5560 dalam Oktafiani, 2016:11-14) bahwa syarat dan sifat yang harus dimiliki oleh petugas restaurant yang baik dan berkualitas diantaranya : (1) Intelligence (akal budi, kebijaksanaan) Hal ini dapat dilihat dari penampilan pramusaji saat operasional di restoran yaitu cekatan, teliti, sangat hati-hati, ramah dan ceria dalam bekerja, (2) Appearance (Penampilan) Pramusaji dituntut berpenampilan yang rapi dan bersih , baik dan menyenangkan, (3) Manners (Adab,sopan satun) Pramusaji harus sopan dan ramah saat menghadapi tamu agar tamu merasa nyaman, (4) Quikness (Kecepatan) Pramusaji harus bergerak dengan cepat karena dalam restoran lebih banyak waktu sibuk dari waktu senggang. Knowledgeable (Berpengetahuan Luas) Pramusaji harus berpengetahun luas terutama tentang bahan makanan di menu. Beberapa syarat dan sifat pramusaji tersebut sesuai dengan penilaian atasan terhadap kinerja pramusaji di Makase Restaurant yaitu penampilan pramusaji, perilaku dari pramusaji terhadap orang-orang di lingkungan kerja, rasa ingin tahu yang tinggi, dan kegiatan pramusaji dalam bekerja seperti persiapan mulai bekerja, kecepatan bekerja, keaktifan dan interaksi pada saat operasional di restaurant.

Berdasarkan pembahasan penelitian diatas, implikasi dari penelitian saya adalah pemberian training melalui atasan dan program yang diberikan oleh hotel untuk semua karyawan departemen hotel merupakan srategi yang baik yang digunakan untuk mengembangkan keterampilan pramusaji yang nantinya akan bermanfaat bagi kepentingan dan tujuan restaurant namun kendala yang yang terjadi saat operasional yaitu keterbatasan bahasa dengan tamu Asia belum sepenuhnya dapat teratasi karena karyawan kurang menguasai bahasa asing yang lain oleh karena itu diperlukan penambahan training bahasa asing sesuai mayoritas tamu yang datang ke Hotel Indigo Bali Seminyak Beach untuk mengatasi keterbatasan berbahasa dengan tamu dan mengurangi kesalahan yang sama serta meningkatkan kekompakan dengan teman kerja agar dapat menyelesaikan pekerjaan dengan cepat. Penilain kinerja untuk pramusaji yang diterapkan oleh atasan sudah mencakup penilaian dari kualitas kinerja pramusaji dan juga berdasarkan karakteristik pramusaji itu sendiri dengan cara ini dapat mengetahui karyawan yang memiliki potensi untuk dapat mengembangkan karirnya

\section{Penutup}

Dari pembahasan yang telah diuraikan tentang strategi peningkatan keterampilan pramusaji di Makase Restaurant diatas maka dapat diambil simpulan bahwa adanya kendala dalam melayani tamu dan strategi peningkatan keterampilan pramusaji :

1. Keterbatasan dalam bahasa menjadi kendala pramusaji dalam melayani tamu saat operasional di restaurant pada saat occupancy sedang tinggi karena tamu berasal dari negara dan budaya yang berbeda-beda dengan membawa karakter yang juga berbeda setiap tamu dan tidak semua tamu bisa berbahas Inggris menyebabkan keluhan, miss komunikasi terhadap tamu dan teman kerja seperti salah penyebutan table number dan pesanan tidak sesuai keinginan menyebabkan slow service dan menurunkan tingkat kepuasan tamu.

2. Strategi meningkatkan keterampilan pramusaji di Makase Restaurant yaitu dengan pemberian training basic, spesifik dan general tentang food and beverage service kepada pramusaji dan 
trainee secara konsisten akan memakasimalkan kinerja pramusaji di restauran, selain itu program dari pihak hotel seperti pelaksanaan uji kompetensi karyawan, kompetisi secara internal dan external juga diterapkan sebagai upaya peningkatan keterampilan karyawan hotel untuk semua departemen. Strategi tersebut sangat berpengaruh terhadap keterampilan pramusai karena meningkatkan rasa percaya diri dalam menghadapi tamu, memperlancar jalannya operasional restaurant dan meningkatkan pendapatan penjualan.

\section{Daftar Pustaka}

Darba, M. D. (2019). Keterampilan Room Attendant Di Hotel. 1-74. Dipetik Mei 18, 2020, dari http://repository.stp-bandung.ac.id/bitstream/handle/123456789/854/201621311\%20\%202019.pdf?sequence=1

Fitria. (2018). Pengaruh Komunikasi Dan Kemampuan Kerja Terhadap Kinerja Pegawai. Economic, Business and Accounting. doi:https://doi.org/10.31539/costing.v2i1.460

Melati, F. (2018). Analisis Strategi Dinas Pariwisata Kabupaten. 1-185. Dipetik Mei 17, 2020, dari http://digilib.unila.ac.id/31185/17/TESISTANPA\%20BAB\%20PEMBAHASAN.pdf

Oktafiani, D. (2016). Strategi Food \& Baverage Product Departement Dalam Meningkatkan Kualitas Pelayanan Di Chrystal Sapphire Restaurant Best Western Premier Solo Baru. Dipetik Mei 19, 2020, dari https://digilib.uns.ac.id/dokumen/download/56348/MjUyNDEy/Strategi-Food-BaverageProduct-Departement-Dalam-Meningkatkan-Kualitas-Pelayanan-Di-Chrystal-Sapphire-RestaurantBest-Western-Premier-Solo-Baru-5.pdf

Pratama, T. A. (2018). Analisis Internal Perum Damri Cabang Lampung Dalam Persaingan Transportasi Antar Kabupaten/Kota. 1-85. Dipetik Mei 18, 2020, dari http://digilib.unila.ac.id/id/eprint/31297

Sa'diyah, I. F. (2018). Perbedaan Pengetahuan Sebelum Dan Sesudah Pendidikan Kesehatan Malaria Dan Analisis Keterampilan Pembuatan Sediaan Apusan Darah Tepi Pada Agen Bom Di Desa Sukajaya Lempasing Kabupaten Pesawaran Lampung. 1-50. Dipetik Mei 18, 2020, dari

http://digilib.unila.ac.id/55390/3/SKRIPSI\%20FULL\%20TEKS\%20TANPA\%20BAB\%20PEMBAHASAN.pdf

Sholichah, Z. (2019). Strategi Pemasaran Yang Tepat Guna Dalam Menciptakan Nilai Pelanggan Pada Kereta Api Kertajaya Dikab. Bojonegoro. 10-42. Dipetik Mei 17, 2020, dari http://repository.unigoro.ac.id/229/2/BAB\%20II.pdf 
Guntu dan Yulianto. 2015. Upaya Profesionalisme Kerja Untuk Meningkatkan Pelyanan Tamu Di The Grand Palace Hotel Yogyakarta.Tersedia pada https://scholar.google.co.id/scholar?hl=id\&as sdt=0\%2C5\&q=Upaya+profesionalism e+Kerja+Untuk+Peningkatan+pelayanan+tamu+di+The+Grand+Palace+Hotel+Yogy akarta\&btnG (diaskses pada 5 april 2019)

Kusuma, Arta Adi. 2013. Pengaruh Motivasi Dan Lingkungan Kerja Terhadap Kinerja Staf Hotel Muria Semaarang. Tersedia pada https://scholar.google.co.id/scholar?hl=id\&as sdt=0\%2C5\&q=Pengaruh+Motivasi+D

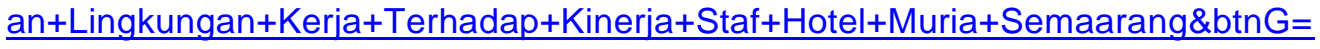
(diakses pada tanggal 11 April 2019)

Moelong.Lexy j.2008. Metode Penelitian Kunatitatif Edisi Revisi.Bandung: Penerbit PT.Remaja Rosdakrya.

Murjianto.2001. Manajemen Sumber Daya Manusia. Bina Atmaja: Bandung

Pearce II, Jhon A, dan Robinson Richard B.Jr (2008). Manajemen Strategis 10. Salemba Empat: Jakarta

Sutrisno,Edi. 2009, Manajemen Sumber Daya Manusia Edisi Pertama. Jakarta: Kencana Media Group.

www.google.com 2019. Peta Hotel Holiday Inn Baruna Bali. Tersedia pada https://www.holidayinnresorts.com. 